\title{
Support for Parenting: Learning to Sustain Theories, Approaches, and Interventions
}

\author{
Sofia Dal Zovo \\ Ph. D student University of Verona \\ e-mail: sofia.dalzovo@univr.it
}

\author{
Doi:10.5901/jesr.2013.v3n7p325
}

\begin{abstract}
The qualitative empirical researches have defined the first parenting support from the sociological point of view (Di Nicola, Donati, Beck) psychological (Bastianoni, Malalgoli Togliatti) and pedagogical (Pati, Viganò,Catarsi, Mortari), as well as objectives and concrete actions on the territory by the centers for families. The research question was: "After the development and progress that led to the current society from traditional to complex, resulting in the phenomenon of urbanization and simultaneous loss of strong ties, typical of patriarchal structures and community centers for families, what kind of function were they performing? What was the real motivation that drives parents to attend these services? "I focused on a case study (25 parents who attended a space family in Verona) and I used the phenomenological method to investigate the phenomenon in reality; semi-structured interviews which helped me to learn how parents perceived the service they have attended, with its strengths and weaknesses, and finally I used the Grounded Theory to analyze the data obtained. The study showed the needs to build the social network, (support and peer comparison, encourage relational networks, social needs, positive atmosphere and openness); educational needs and change (support in managing the daily educational, reassurance given by professionals in attendance, acquisition of educational skills, acceptance of its limits); relational needs with educators (personal relationship and lasting) playful recreational needs (interruption of the daily routine, time to be with his/her child).
\end{abstract}

\section{Introduction}

It is clear that our age is strongly characterized by the speed and dynamism of changes that have affected the family. First of all the symmetry that characterizes today, thanks to the spouses' place of education and increase awareness and women's rights, is subverting the traditional conception of the family that reigned until the fifties, that the limited within the home (Golini, 1998); also the reality of the modern family is diffused. As discussed in "Il Corriere della Sera" (1999): << The children of 2000: an increasing number of children from 0 to 13 years with both parents employed (39.3); decreases the number of children with busy father and housewife mother (41.3), increase the children without siblings (26.7) or with a sibling (52.5); decrease children with 2 or more siblings (20.6) [...]. More people sun (???) (21.3); increase couples without children (20.8); increase the families of 2 components (26.4) [...]. Introducing "the couple commuter" are 2 and a half million people, $4.5 \%$ of the population living for long periods outside their normal home, for reasons of work or study. Commuters by choice or by necessity. There are also new types of families: those consisting of single parents just do not widowers, the free unions and reconstituted families, which accounts forthree and a half million families, out of $10.4 \%$ of the Italian population >>. It is essential at this point, to penetrate deep into the changing trends of the family in Italy, in order to achieve social policies specifically oriented to the family ( Di Nicola, 2002). Vital consideration at this point is concrete social policies that are able to take care of the family: a social policy appropriate must move first in the direction of the promotion and compatibility between care work and productive work (Di Nicola numero monografico di Sociologia e politiche_sociali). This latter consideration is needed to clear the field by a series of clichés, which sees any action to support parents as a response to a growing inability or difficulty of adults to achieve this task. The family should not be classified as irrelevant and incompetent compared to other educational agencies, but it is necessary to approach to parenting with different eyes and different levels of sensitivity: while in traditional society is born with certain advantages (social class, religion). Here are the benefits must be conquered individually therefore the normal biography turns into "biography of choice "in" biography of yourself " (Beck, 2000). In fact, the most common mistake that quite often you fall is that you have always thought and said that it is mothers and fathers for "nature," as if their skills were innate, biological. Instead parenting skills have always been culturally mediated, for which they required help, support are charged with meaning: it is the product that a company is asking for their constant self reflexivity. It is also to be abolished also the mistaken belief that supports the existence of dysfunctional families and unproblematic: it is a belief that families "normal", "perfect" would be devoid of problems: all of this is false. It is critical that the outcome of the 
adaptive family processes is perceived not so much as the absence of conflict, hardship and suffering, but the way in which conflict, distress and suffering are negotiated and addressed (Fruggeri in Bastianoni, Taurino, Zullo 2011). In this regard therefore becomes important to give a definition of centers for children and parents, (which are different from spaces for children), so called because they provide service in the presence of parents or other familiar with the children, to share a few hours playing time or simply socializing with other children and parents outside the home, with the objective of promoting the strength of the relationship and offer to both children and parents an opportunity of social contacts, dialogue and communication (Musatti, 2005). Within these services, families can be helped in the rediscovery of their "potential parental," certainly a wealth of resources necessary for future generations: an effective intervention must therefore consider the possibility of restoring the balance essential within of his family by supporting parental action, doing what they can to help each pair to re-discover the knowledge and beauty of their resources (Malagoli Togliatti, Tafa, 2005).

To support parenting is meant the set of educational activities aimed at families who have the common purpose of accompanying families in their becoming critical in the early stages of evolution and by capitalizing on the resources, the knowledge, the ability to build meaningful relationships with the outside world (Milani, 2001). Therefore, the purpose of these services is to strengthen parents to understand that the problems with the child are normal and common. They were born as places to meet and socialize, discussion and debate, sharing of personal experiences without transpose the advice of educators and specialists in a passive way, but focusing on the mode of active confrontation with other parents who are experiencing their own doubts (Mantovani , 1999). The pedagogy as a discipline in this regard should strongly support the goal of strengthening the couple through empowerment put in the dyad condition to decide their internal rules most suitable to regulate the communication, dialogue and their life choices (Pati, 2005). Not surprisingly, its torque you are talking about: according to the latest report of CISF, 2011, following an investigation made by Istat on the Italian family, the idea of family is challenged by the new idea of torque. Based on socio-demographic data showed that there is a growing number of unmarried couples (50.5\%) increase couples without children or with one child, and in general families shrink in number, are privatized more and more. The pair is definitely becoming an alternative way of life to the family (Donati, 2011). It is therefore to rethink the whole issue of parenting support, to be understood in terms of both economic and psychological training. In this regard, a commitment is necessary including financial support, which responds to the need to educate the relationship, even before the parents decide to live together and have children. The difficulties of living together in fact, should lead to the organization of training courses, which facilitate the acquisition of greater self-awareness and opportunities to learn from others (Catarsi, 2003). This suggests that family life is not static, but on the contrary it grows, changes, interruptions and undergoes crisis and is subject to revisions and adjustments, pursuant to become agents of individuals in it (Pati, 2006). Citing Winnicott, then, how to be parents, "good enough" leveraging ties with the territory? What is the role of Centers for Children and Parents? The current services that perform the function of parenting support, have gone from a welfare approach to a style cooperative, through the laws 285/1997 and the law 328/2000. First the revolution was the real sharing of functions and responsibilities on the part of educational institutions, which made the family aware of its importance, as it not only user who receives services, but it becomes an active protagonist, reaching the true activation of resources within the family. But it is also worthwhile to bear in mind that the intervention for each individual household cannot be standardized and that parents can therefore be looking for "experts" to ask for advice and places to discuss issues related to the relationship with their children. In this they can reflect on the tools they possess, but which at times are unaware of or bring into question the very existence: the intervention in this case should serve to support them, not only to adopt attitudes appropriate to the aims they pursue, but also the type of people they are (and the type of person whom the child would be); encourage them to come to an awareness and an emotional attitude which is positive for both (Malagoli Togliatti, Tafà 2005).

\section{Research design}

The research was conducted on the parents who attended the Spaces Family Pescantina (Verona) from May to July, 2012. These spaces used to support parents who gave birth in 1998 as a as a local services Ulss 22, on an experimental basis by the will of the town, which is interrogated to understand how to be close to the families of the area. These services have emerged as the spaces and times dedicated to adults, to get together and to discuss about child raising, making room for boys and girls with the aim of the game for them, socialization and growth. I want to emphasize that it is the particular nature of Space Family, as a place of play for children and adults, host and listening, where you learn to actually enjoy being together between parents with their child, to get out of your own four walls for open to the sharing of experiential knowledge, in an atmosphere of openness where there is a space created specifically to foster the 
relationship. Briefly illustrate some goals are to:

1. offer a place suitable for physical socialization, through the involvement of parents in the discovery and management of activities and experiences that will enrich their educational strategies;

2. foster the spontaneous aggregation of families by offering a time during which we can compare the different experiences of the "parent craft";

3. Promote links between the educational, social and health care for the family and young children, for better integration and enhancement of existing resources, expanding its network of relationships and knowledge.

\section{Research Question}

As aforesaid, the aim of the research was to understand what motivated parents to attend the Parent Child Centers. Put it differently, after the development and progress that led to the current company from traditional complex, resulting in the phenomenon of urbanization and simultaneous loss of strong ties, typical of patriarchal structures and community, what was the real motivation that drives parents to attend these spaces? "

\section{Methodology}

The research that I conducted according to qualitative methods, it is often subjected to criticism, as it is considered to lack methodical principles, capable of ensuring an adequate epistemic rigor, without which it is impossible to arrive at valid knowledge. Basic becomes then define a method that can lead to the development in knowledge, which they can recognize the validity, as acquired through rigorous research procedures (Mortari, 2010). Therefore, the most appropriate method that I have adopted, which takes epistemic value is the phenomenological method, Which performs its Peculiarities on the principle of loyalty to things. The phenomenological method (Mortari 2010) can be summarized by including these features:

1. The phenomenology takes as its object of investigation the experiences, and their life experiences are at the heart of qualitative research in the social sciences;

2. Leading the phenomenology is the tension to build as a rigorous science, and this is the primary aim of the qualitative research undertaken to gain a clear scientific credibility;

3. The quality of the phenomenology, as Levinas claims is to be a philosophical method and because educational research is looking for a rigorous method, the phenomenological can be a valid point of reference.

\section{Tools}

Using the conversational interview, as a central tool, I submitted the sample of 25 participants in my research. Interview is a way of speaking directly to another driven by some specific questions, prepared in order to probe the research question without the other caged within well-defined patterns. It explores the world of experience which includes the socalled "practical" (parents, educators, and teachers) and the knowledge they produce is not disconnected from reality. , on the other hand, it is precisely through the story and the opportunity to tell their life experience, exposing their strategies put in place, therefore, the one that emerges can be considered valid to reconstruct the practical knowledge. For this reason, it is necessary to take care of the subjects during the search,

starting from the posture of the researcher: not to be judgmental, but cozy, but also be able to consult each other in a relaxed manner without usurping spaces. From here began my research: I have used a semi-structured interviews in which I placed under the participants. The pattern of the interview consists of ten questions that dealt with the topic under various facets. The first questions were intended to enter into with the parties a "primitive" form of contact, of relationship and to enter more familiar with the interviewee ("How old is your baby?" "How long have you attended this service? "'" in what does it consist of? "' How did you learn of the existence of this service? "). Then I focused on the experiences of the subjects, the experience that this person has had from attending the Space Family ("What did you like?"). Moreover it seemed essential to demand the reason that led the respondent to take part in this type of service ("Why did you go there?") and although the attendance of this service may have been of help, enrichment ("So I help you?"). Finally, I wanted to take this relational aspect that has been created within this space family, both the personal and close relationship with the teachers present ("How was your relationship with the teachers?"), Whether overall between parents and educators ("What kind of relationship has been established between teachers and parents?"). Last but only from a chronological point of view, I wanted to change the role of parent, the interviewee. Specifically, I am referring to the fact 
that if the respondent, in participating in this type of services, such as the Centers for Families, has been able to learn something (" Have you learned something as a parent?"). It should be kept in mind that what is at the basis of the analysis of the interviews, calls for absolute loyalty to the descriptions provided by the participants, the parents. It is also true that by approaching the words of the parents surveyed, the effort was to capture as much as possible their experience, although it is clear that much remains to be explored. According to the trace of the research that I have mentioned, proceeding to analyze the interviews was my job (Mortari 2010):

I have highlighted the important portions of text, meaningful units of description with emphasis, and exclude others, judged to be less relevant to the focus. Then I have given a brief description of each unit to decide the validity of the account produced, ie the meanings welded in brief descriptions although there are no procedures tested techniques: each elaborates the subjective and unique. Later, I put the first synthetic conceptualization to each unit called label (label), which should be faithful to the contents of an utterance of the source text, how about the essential quality without adding anything and without making interpretations. The next phase aims to make a comparison between these texts and to begin to single out the essential features of what has given parents, participation in the Space Family. It was made a transversal analysis of the texts, so as to be able to compare the networks of meaning that are basic in each text, in order to bring to light the extended quality of the various texts. It would be simplistic, however, to think of having caught the essential quality of the phenomenon considering only what it is extensively shared, and therefore also the so-called partial quality are thus identified and highlighted, because the meaning of a phenomenon constitutes both an essential level, and extensive quality, both meanings of the peripheral. We then move on to the analysis of labels and categories emerging through the coding system. The coding system is used to make a synthesis of the main points, calling into question the labeling process since there made. The last process involves the return on the analysis of text units, that should allow you to see what they are and then to regroup in macro categories all units of text discussing a certain topic.

\section{Results}

An analysis of the interviews, revealed several types of labels, which then led to a division into four main categories which I will explain below: educational needs and change, relational needs with educators, social needs of network construction and recreational needs-games.

Table 1: Educational Needs and change

\begin{tabular}{|l|c|c|}
\hline \multicolumn{1}{|c|}{ Labels } & Instances & Total \\
\hline Support in managing the daily educational & 21 & \\
\hline Reassurance by professional present & 20 & \\
\hline Acquisitional of educational skills & 8 & \\
\hline Managing emotions & 7 & \\
\hline Problem managing & 8 & \\
\hline Acceptance of its limitations & 6 & 70 \\
\hline
\end{tabular}

In this macro category I have enclosed all the labels which referred to 'help in the education of children, through targeted activities that were made within the service and especially also with regard to the acquisition of new parenting skills.

\subsection{Support in managing the daily educational needs}

"Not all, but speaking for myself, maybe [I ]have the imagination to propose who knows what to their children, but here I learned how to do new things, take cues." (Int. 20)

Other parents, for example, after attending the Centre, were able to reproduce some activities within their home. Definitely not to be able to propose activities during that time devoted to children in the parents have aroused a strong sense of inadequacy, inferiority, for what concerns parenting skills. However, to get involved and share their views inspired by the various practices and activities according to my point of view was very useful because they felt enriched, both in terms of human relations, and educational skills. Participate in this center gained confidence in themselves and their parenting skills, for which, they felt strengthened and able to better manage their relationship with their child. 


\subsection{Reassurance by professionals present}

"I then cut people for this job, so it was really nice, and in fact still with their mothers when we meet we remember these moments because they were things alternatives" (Int.13)

These results are also relevant meetings with specialists (pedagogists, psychomotor therapists) who were invited to participate from time to time at the Center where parents had an opportunity to learn from the professionals through observing the interaction they made with children. The experts present were some real points of reference for parents. They would rely completely, as well as advice and exchange of opinion, even with regard to the vision, they could have children: valorized their strengths, but also invited to reflect on the difficulties of the child, urging both to improve.

\subsection{Acquisition of educational skills}

"You always learn by talking to other people, with other mothers, see more than anything else that is not only your child who is in a certain way, and then widen your horizons" (Int. 16.);

Here it is made explicit that the acquisition of skills education has taken place within the Centre, through the comparison with professionals and educators always through dialogue and relationship. But the acquisition of such skills is also managed through the exchange of views and opinions that has occurred between the parents themselves, among peers. Therefore it became evident that especially the comparison between peers, parents instil in a feeling of reassurance and serenity. It also reiterated the expansion and enrichment of its knowledge, its points of view thanks to the comparison.

\subsection{Management of emotions}

"It gave me so much, to avoid anxieties, concerns, especially of not being up, they do not know enough about your child, not being able to understand, especially with the first, because of so many behaviors." (Int . 21)

Attending the center as an emerging parent as has been very positive in the first place as it represented a point target reference, and secondly, it meant a reduction of anxieties and concerns, and the birth of reassurance and confidence. This means that the parent in question certainly had the fear of not covering so its full parental role. It is known very well the insecurity of not knowing well the child and not being able to understand some of his behaviors feeling the need to support and help.

\subsection{Problem Management}

"He also did a period biting, pulling hair, a little 'aggressive say, and I know I was ashamed even with other moms and then he targeted a child forever. Instead of going to them that I have compared with other moms and that the other children have also passed that stage there "(Int. 22)

In these words emerge all the feelings of shame and inadequacy that characterize the experience of this mother: the aggressiveness of the child created in her discomfort. Then, attending the center, and then through, as she cites the exchange of opinions and advice with other parents made sure of being able to overcome his feelings of discomfort and embarrassment, first of all, finding solace and encouragement and a later stage, also new educational practices in the attempt. . Surely this has benefited for the personal serenity and enrichment of skills for this mom, which was not considered by the educators of the Centre, but was helped to intervene and work on the child's behavior, and to be treated as a normal phase of growth.

\subsection{Acceptance of one's limits}

"If you start from the assumption that you're always right because you are the parent is better that you're home" (Int. 14)

This piece of interview is particularly important because it shows that the position is wrong that very often taking certain parents of "untouchability", of absolute reason and power. What emerges is the fact that you should put yourself in the game and in discussion: the attendance of the Center has helped to consolidate a more dialogic, leaving room for 
possible constructive criticism and comparisons, which were essential for all participants. In particular, the parent highlights how truly listen to the teachers has led to have a different view of things, opening the way to a new awareness and making him work on himself to improve their educational skills. Surely what the parent has been able to understand is that very often really listening to each other and confront a growing experience is that the Centre gave him the chance to live.

Table 2 : Relational Needs with educators

\begin{tabular}{|l|c|c|}
\hline \multicolumn{1}{|c|}{ Labels } & Instances & Total \\
\hline Building a face to face relationship & 20 & \\
\hline $\begin{array}{l}\text { Construction of a long lasting personal } \\
\text { relationship with the social worker }\end{array}$ & 30 & 50 \\
\hline
\end{tabular}

This macro category proved to be very important for the parents themselves because they build the relationship with the social worker in a very constructive and inspiring way. It is remarked that building a meaningful and valid relationship result in the availability of the social workers outside of working hours and facilitating continuity of the service.

\subsection{Building a relationship face to face}

"It was beautiful, the people are wonderful, because it was not the social worker that gives you the rules, [they] simply gave a guide." (Int.2)

These words clearly as attending the Centre has accounted for this parent a 'positive experience and how he conserves in social workers respect and trust, expanding its positive opinion to the personal as well as professional lives. It is stressed that the social workers also within the Center does not embody an authoritarian role, as holders of absolute power, but rather as they would encourage a relationship geared to growth and exploitation of participants and their individual skills. This was possible thanks to a deep mutual relationship that has allowed to work on the participants, so that they felt free to express themselves, and bring their expertise in the field. Therefore emerges as the social workers embody the role of facilitators, without forgetting that the real focus were on the participants.

\subsection{Construction of a long lasting personal relationship with the social worker}

\section{"Sometimes even the confidence and friendship, [... it's well worth going there" (Int. 7)}

This parent has stressed that his personal relationship with the social workers has been very positive, as it has turned into a bond of trust and even friendship. . She pointed out that it is really "worth it" to attend the center, because the creation of these meaningful connections has contributed to the enrichment of your mother with regard to the educational skills, but because she found the people to be valid under the human and professional profile, who were able to ride it with competence and kindness, supporting it and supporting it when he needed it. To the Centre of the rest was very important to be able to support the creation of strong links, because the parents were able to find support appropriate to their needs, thanks to this long-lasting bond that has developed with the social workers.

Table 3: Need for construction of the social network

\begin{tabular}{|l|c|c|}
\hline \multicolumn{1}{|c|}{ Labels } & Instances & Total \\
\hline Answer the needs of sociality & 33 & \\
\hline Support and peer comparison & 36 & \\
\hline Positive atmosphere and openness & 7 & \\
\hline Opportunity for children to attend agemates & 7 & \\
\hline Encouraging relational networks & 12 & 95 \\
\hline
\end{tabular}

This macro category got by far the largest number of occurrences, so self-explanatory function and the reason why parents attending the Spaces Family. They were very often alone and struggling with a bewildered child in front of them with great commitment. Thus, having a child need someone the people they trust, on their but only to support than to replace. 


\subsection{Support and peer comparison}

With the help of everyone we talked and we were helped" (Int. 9)

Even in this interview enhancement of mutual aid that has characterized the participants of the Centre was noticed. This attitude has contributed massively to feed the network of support that parents themselves have created, to help each other, using as a primary and fundamental dialogue. Speaking honestly, exposing their doubts and problems, but also expressing curiosity or telling their experience has made us aware of each participant's strengths and weaknesses. Good cooperation where everyone is involved in an active way was emerged in the relationship. Even the fact of being all on the same level has produced a sort of equal cooperation that has led to excellent results both in the relational level and the level of acquisition of educational skills, always under the guidance of competent educators who organized these moments of meeting.

\subsection{Answer to the needs of sociality}

"Just being in the company with other moms, it is bad to stay at home all alone" (Int.8)

Also in this interview, we understand that it was very strong, as mentioned earlier, the need for construction of the social network. What makes you think this is just the need for companionship, spend hours together with others, the need to socialize, to forge relationships is part of the social nature of human beings. These words also underline the sadness of isolation and loneliness in the home. In this context, the Centre has indeed allowed to make a path more in-depth on awareness and on the dynamics of parenting today, but also responded to those needs of sociality that were present in the area, although often in silent form, favoring the creation of meaningful relationships Positive atmosphere and openness

"Seeing the atmosphere of openness, I was encouraged to push and I slowly began to acclimatize" (Int.8)

These words clearly show how the climate of openness pave the way to push to start a path of knowledge, which then contributed to an educational journey that ended in an authentic way for the participants. It was the climate of openness, skillfully created by the educators and other parents present to promote the integration of all parents, even the most timid and doubtful. Therefore, the positive atmosphere of openness that has characterized the meetings of the Center, it was definitely crucial to be able to gain the trust and interest of the people who wanted to fit in, motivating them to get involved, at least at this early stage.

\subsection{Ability of children to attend peers}

"He had done the nursery, so to make it interact and I had known of this service." (Int.23)

Another reason that led parents to attend the service was just to give an opportunity to the children who did not attend the nursery, to have them interact with their peers. Most likely the parents must have thought at the beginning that the service was aimed at children, just to take advantage of the possibilities of this place where they can do to meet their children. Only later through the association with the Centre came to understand that the activities of the service were aimed at themselves, the real beneficiaries of the interventions from the support and guidance of the social workers. However, it was decisive, in my opinion, the fact that there was adequate space and experts for the treatment and activities of the children, because, for parents, also seeing their enthusiasm and their interest in having to continue to participate, was the impetus further to the parents themselves to continue to attend various meetings.

\subsection{Encouraging relational networks}

"Just to experience this moment of aggregation" (Int. 5)

In this excerpt of the interview is emphasized that the primary motivation for the parents who participated in the Center was the desire to meet and be with new people with whom to share the experience of being a parent. This is clearly motivated by loneliness or isolation that the mother is experiencing postpartum, or simply a poor social network you can rely on. Create networks of relationships was important for users to be able to have an opportunity for dialogue 
and exchange of advice, discussion and also of fun as well as meetings with experts.

Table 4: Needs recreation - and playful

\begin{tabular}{|l|c|c|}
\hline \multicolumn{1}{|c|}{ Labels } & Instances & Total \\
\hline Stop the daily routine & 9 & \\
\hline fun time to spend with his child & 12 & \\
\hline Curiosity & 3 & $\mathbf{2 4}$ \\
\hline
\end{tabular}

Finally, in the latter macro category are inserted labels that enclose the need of parents to interrupt the daily routine, to approach the service simply out of curiosity or interest, or for wanting to spend time alone to his son.

\subsection{Stop the daily routine}

"You did something different from the usual routine mother and child" (Int. 24)

Here, too, is highlighted the importance of the Centre, as a promoter of activities and interventions, targeted to parents, as well as an opportunity to break the daily routine, where mothers could find social ties, exchange of experiences and peer support, as well as a moment where you can get distracted by the problems and things to do in the day. Therefore, in addition to having played a role of parenting support, the Center has also encouraged gatherings and meeting between parents, who were eventually able to find a service designed specifically for their education.

\subsection{Fun time to spend with a child}

"Being more formy son, I am convinced that he did very well" (Int.20)

Another element that is emphasized is the satisfaction parents derived from being with their children during the time spent at the Centre. Devoting oneself completely to the child, without interruption triggered by external factors, has been instrumental in building the relationship. The Centre has provided an opportunity for mothers to cultivate a unique way at least once a week meet and discuss with their child.

\section{Curiosity and interest}

Finally, we note here that the Centre has been able to be something that affects people's attention and challenging, perhaps because they failed to grasp the true heart of the needs of the parents. First of all, the support from other parents, born of the constructive dialogue between equals, was responded to the need for social networking.

In addition, as recipients of the service, parents allowed to work with themselves, with the aim to become aware of their educational practices and improve it through the mutual exchange of ideas and advice. The curiosity was given by the novelty of the service that did not disappoint the expectations of the participants: the majority admits that she finds herself very well, he had also built friendships with mothers and lasting relationships with the educators. In addition, as can be seen from the interviews, is manifested the will of the parents to attend it again if they also have children in the future. The service has therefore centered in the middle of its target.

\section{Discussion, limitations and implication of the study}

At the end of this work, I am aware that there would still be much to say about this issue. Supporting parents in Italy is finding fertile ground only for a while 'time now, although we are seeing a sprout more and more intense interventions on this issue. The results of the research that I have conducted have finally an answer to my research question: "Why do parents go to the Centers for families?" The result of the interviews that the information I have provided has been unanimous: first of all for the needs of parents of confrontation and encounter. As it is clear from the analysis, the comparison the common thread of all cases considered. For too long parents, once failed the strength and support that infused a community network, have suffered from loneliness, uncertainty, a sense of inadequacy and inferiority compared to previous generations. For too long they have been convinced that they must do it alone at all costs, as not to obscure the appearance of "perfect family" who knows exactly handle problems and unexpected. All this has led to loneliness, 
isolation, depression, silent, being accompanied by fears of not being up to own and operate their children, not knowing who to rely on. As a future proposal certainly that of leverage on the distribution and promotion of services to support parents in the territory or in areas where it is still considered a good and interesting possibilities, such as urban areas, and in other bands, maybe provincial, where mistrust and closure are certainly still very present and high, would benefit those directly involved: the parents. The new families that are forming; parents with teenage children in whom the balances are more delicate; couples who are living the experience of a separation or a divorce behind and have to redefine the relationship with their children: are countless situations and cases for which a service of this kind could lead support. Items that are most highlighted by the parents the need for sociability, the equal interchange of advice and educational practices, the exchange of opinions and experiential knowledge, support in the management of children. All these in a context in which predominates a climate of acceptance and openness to the participants and where it is possible to build a lasting relationship with the teachers' present, promoting at the same time before the whole meeting between the parents. Great importance also took the interventions of experts, activities and workshops led by educators and child psychologists, but the real stars of the Center were the parents and their children. the support that is provided by this type of service, is not practical to replace by educators, in that role that primary education may hold only the parent: support covers only the value of help and comparison. Just starting from the awareness that the possibility of failure is always present in educational contexts, you can start a real process of growth and improvement, through a mutual enrichment derived from the comparison, much sought after by today's parents. It is also evident that the service grasp points, and upgrade their education and skills of that particular family, of those individual parents to arrive, with patience and perseverance autonomy. The dominant element should instead be the co-construction of a path, the being able to act as a guide. Therefore, since the limit of this research, based on the investigation of a single center for families, you could expand the investigation and to extend it to more services forming part of the province, or even regional.

\section{References}

Bastianoni P., Taurino A., Zullo F., (2011) " Genitorialità complesse, interventi di rete a sostegno dei sistemi familiari in crisi" Unicopli, Milano

Beck U. ( 2000) "I rischi della libertà. L'individuo nell'epoca della globalizzazione", II Mulino, Bologna

Catarsi E. (2003) "Essere genitori oggi" Ed. Del Cerro, Pisa

Comune di Pescantina ( Verona), documento (1998): "Gli Spazi Famiglia: sostenere la genitorialità, servizio educativo territoriale" Ulss 22

Corriere della Sera ( 30 marzo 1999)

Di Nicola P. ( a cura di ) (2002) "Prendersi cura delle famiglie" Carocci, Roma

Di Nicola "Famiglie e politiche sociali di welfare" numero monografico di Sociologia e politiche sociali anno 1, n.3

Donati ( a cura di) (2011) "La relazione di coppia oggi" Rapporto CISF sulla famiglia Ed. Erikson Trento

Golini A. ( 1988) "Profilo demografico della famiglia italiana" in La famiglia italiana dall'Ottocento ad oggi Ed. Laterza Bari

Malagoli Togliatti M. , Tafà M. ( a cura di) ( 2005) "Gli interventi sulla genitorialità nei nuovi centri per le famiglie, esperienze di ricerca", FrancoAngeli, Milano

Mantovani S. Andreoli S. (1999) "Bambini e adulti insieme. Un itinerario di formazione" Ed. Junior Bergamo

Milani P. (2001), Manuale di educazione familiare, Trento, Erikson

Mortari L. ( a cura di) (2012) " Dire la pratica, la cultura del fare scuola" Bruno Mondadori Milano - Torino

Musatti T.(2005) "Un luogo per bambini e genitori nella città" II Mulino Bologna

Pati L. ( a cura di) (2005) "Educare alla genitorialità", LaScuola, Brescia

Pati L. Prenna L. ( a cura di) (2006) "Percorsi pedagogici ed educativi nell'opera di Norberto Galli" Vita e Pensiero, Milano 